\title{
Co-La (Cobalt-Lanthanum)
}

\section{H. Okamoto}

The Co-La phase diagram in [Massalski2] was redrawn from [1974Ray], which was based on [1967Bus] with an additional phase $\mathrm{Co}_{19} \mathrm{La}_{5}$. This additional phase was not shown in a partial phase diagram (0-30 at.\% La) reported by [1974Kha].

Figure 1 shows the Co-La phase diagram assessed by [2008Wan]. The phase diagrams of [1967Bus] and [1974Ray] were used as the basis of this evaluation.
1974Kha: Y. Khan, Intermetallic Compounds in the Cobalt-rich Part of the R-Cobalt Systems $(\mathrm{R}=\mathrm{Ce}, \mathrm{La}, \mathrm{Ce}-\mathrm{La})$, J. LessCommon Met., 1974, 34, p 191-200

1974Ray: A.E. Ray, Cobalt, 1974, (1), p 13-20, as quoted in [Massalski2]

2008Wan: C.P. Wang, J. Wang, X.J. Liu, I. Ohnuma, R. Kainuma, and K. Ishida, Thermodynamic Assessment of the Co-La and Mo-La Systems, J. Alloys Compd., 2008, 453, p 174-179

\section{References}

1967Bus: K.H.J. Buschow and W.A.J.J. Velge, Phase Relations and Intermetallic Compounds in the Lanthanum-Cobalt System, J. Less-Common Met., 1967, 13, p 11-17

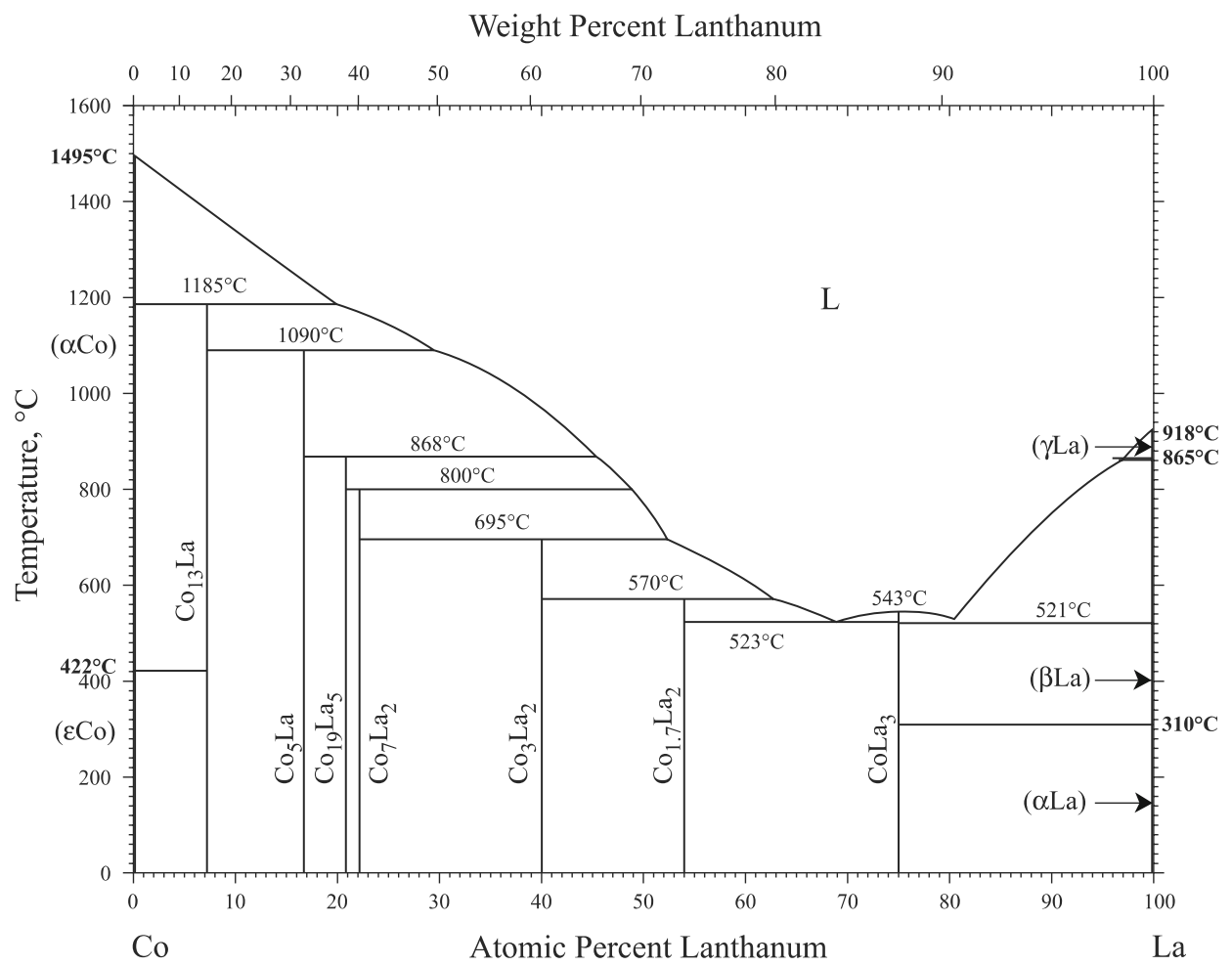

Fig. 1 Co-La phase diagram 